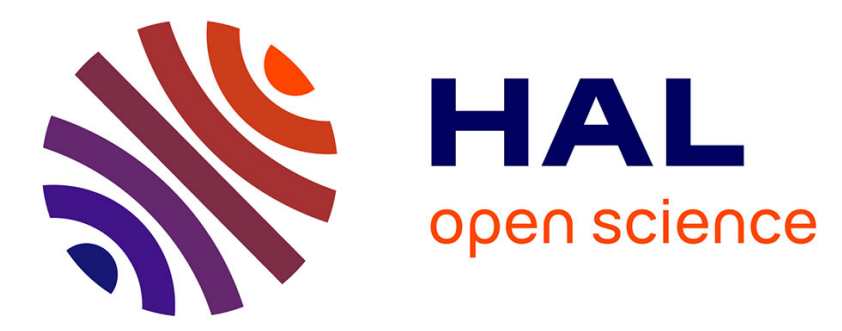

\title{
INELASTIC RESPONSES OF SWOLLEN NITRILE RUBBER UNDER CYCLIC LOADING
}

Mei Sze Loo, Jean-Benoit Le Cam, Andri Andriyana, Eric Robin

\section{To cite this version:}

Mei Sze Loo, Jean-Benoit Le Cam, Andri Andriyana, Eric Robin. INELASTIC RESPONSES OF SWOLLEN NITRILE RUBBER UNDER CYCLIC LOADING. Rubber Chemistry and Technology, 2018, 91 (1), pp.136-150. 10.5254/rct.18.83713 . hal-01833209

HAL Id: hal-01833209

https://hal-univ-rennes1.archives-ouvertes.fr/hal-01833209

Submitted on 7 May 2020

HAL is a multi-disciplinary open access archive for the deposit and dissemination of scientific research documents, whether they are published or not. The documents may come from teaching and research institutions in France or abroad, or from public or private research centers.
L'archive ouverte pluridisciplinaire HAL, est destinée au dépôt et à la diffusion de documents scientifiques de niveau recherche, publiés ou non, émanant des établissements d'enseignement et de recherche français ou étrangers, des laboratoires publics ou privés. 


\title{
INELASTIC RESPONSES OF SWOLLEN NITRILE RUBBER UNDER CYCLIC LOADING
}

\author{
Mei Sze Loo, ${ }^{1}$ JeAn Benoît Le CAm, ${ }^{2}$ Andri Andriyana, ${ }^{1, *}$, Eric Robin ${ }^{2}$

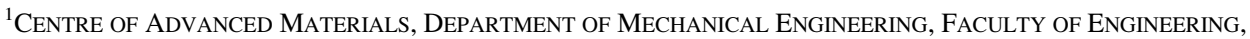 \\ UNIVERSITY OF MALAYA, 50603 KUALA LUMPUR, MALAYSIA \\ ${ }^{2}$ UNIVERSITÉ DE RENNES 1, INSTITUT DE PHYSIQUE DE RENNES UMR CNRS 6251, CAMPUS DE BEAULIEU, BAT. $10 \mathrm{~B}, 35042$ \\ RENNES CEDEX, FRANCE
}

\begin{abstract}
Palm biodiesel is deemed a promising future fuel substitute for conventional diesel fuel. In line with this perspective, necessary changes in the existing diesel engine system are expected in order to address the issue of material compatibility. One typical degradation observed in rubber components exposed to aggressive solvent such as palm biodiesel during the service is swelling. Thus, the investigation of the effect of swelling on the mechanical response under cyclic loading is prerequisite for durability analysis of such components. In this study, filled and unfilled swollen nitrile rubbers are immersed in conventional diesel and palm biodiesel baths until a 5\% swelling level is achieved. Both dry and swollen rubbers are subjected to uniaxial cyclic loading tests. The analysis of the mechanical responses has shown that swelling decreases inelastic effects such as hysteresis, stress softening, and permanent set. For both dry and swollen rubbers, fillers are found to have significant effects in the inelastic responses, whereas the effects of solvent and loading rate are comparable.
\end{abstract}

\section{INTRODUCTION}

Acrylonitrile-butadiene rubber (NBR) is used extensively in a wide variety of industries because of its excellent properties and commercial availability. NBR also becomes a popular choice for newly developed composites and blends owing to its high strength coupled with oil- and fuelresistance characteristics. ${ }^{1-3}$ During the service, which often involves fluctuating loading, rubber exhibits strong inelastic responses. ${ }^{4,5}$ These inelastic responses include hysteresis, stress softening, and permanent set. The hysteresis is identified as an appearance of a loop in the stress-strain curves when the material is subjected to a cyclic loading. Although hysteresis is commonly related to heat dissipation, Martinez and coworkers ${ }^{6}$ found that the hysteresis loop can be observed in the mechanical response of rubber without any dissipation. The most evident sign that stress softening has taken place can be concluded from the stress-strain response, where one can observe that a lower consecutive stress is needed to achieve the same amount of strain generated from the first loading phase. Stress softening, also known as the Mullins effect, was named after Mullins and his coworkers, ${ }^{7}$ even though Bouasse and Carrière ${ }^{8}$ reported the occurrence of stress softening in rubber vulcanizates 40 years earlier. Despite extensive work on the Mullins effect, the origin of this phenomenon is not fully understood. ${ }^{4,9,10}$ After the material is released from stretching, a certain residual deformation remains and is often referred to as permanent set. The permanent set depends on the amount of fillers, and recovery from permanent set is possible by solely leaving it aside for a certain period of time or through exposure of temperature and solvent. ${ }^{4,11}$

In automotive industries, attempts have been made to search for an alternative source of energy to replace depleting fossil fuel sources. In this line, palm biodiesel is considered a promising future fuel substitute. ${ }^{12-14}$ Indeed, in terms of energy balance, palm oil has the highest yield compared with other energy crops. ${ }^{12}$ However, the compatibility issue between rubber components and palm biodiesel remains a major challenge, especially when NBR is commonly used in automotive 


\begin{tabular}{lccc}
\hline & \multicolumn{3}{c}{ Immersion duration, $\mathrm{h}$} \\
\cline { 2 - 4 } Solvent & Unfilled NBR & $25 \%$ filled NBR & $40 \%$ filled NBR \\
\hline B0 & 100 & 160 & 300 \\
B100 & 24 & 50 & 100 \\
\hline
\end{tabular}

parts. ${ }^{15,16}$ Numerous works have reported nonnegligible degradation of rubber properties, including in NBR, upon exposure to palm biodiesel. ${ }^{17-22}$ The corresponding degradation is initiated through diffusion of solvent into the material, which leads to swelling. ${ }^{20,23}$

Although the need to consider swelling with regard to the durability analysis of rubber components is critical, only a few studies exist in the literature that have investigated the properties of swollen NBR exposed to palm biodiesel. ${ }^{20-22}$ Andriyana et al. ${ }^{20}$ investigated the stress softening of swollen NBR under compressive cyclic loading, whereas Chai et al. ${ }^{22}$ extended the investigations for different rubbers swollen in biodiesel for various immersion durations. A recent study of swollen NBR under uniaxial tension fatigue load has been reported. ${ }^{24}$ Note that the abovementioned works did not consider the effect of carbon black content coupled with swelling on the general inelastic responses of the materials.

The present article can be considered as the first attempt to investigate the effect of swelling, type of solvent used to induce swelling, filler, and loading rate on the mechanical response of NBR under uniaxial cyclic loading condition. More precisely, the emphasis will be placed on the inelastic responses including hysteresis, stress softening, and permanent set classically observed in dry rubber under cyclic loading. In the second section, detailed experimental work is provided, whereas the results are presented and discussed in the third section. Finally, concluding remarks are given at the end of the article.

\section{EXPERIMENTAL PROGRAM}

\section{MATERIAL AND SPECIMEN GEOMETRY}

The material considered here is a class of NBR filled with $0 \%, 25 \%$, and $40 \%$ volume fraction of carbon black. The NBR contains $18 \%$ of ACN with N326 grade of carbon black fillers and is cured by sulphur. The specimen has the geometry of a dumbbell with dimensions in accordance with ASTM standard D412-C: the specimen is $6 \mathrm{~mm}$ in width and $2 \mathrm{~mm}$ in thickness. All specimens used in this investigation were purchased from the Malaysia Rubber Board. ${ }^{25}$

The specimens were swollen through stress-free swelling immersion in a solvent bath at room temperature until a 5\% swelling level, on the basis of volume change, was achieved. The solvent used was the conventional diesel (B0) and palm biodiesel (B100). Table I shows the immersion duration needed for each rubber with different amount of fillers to achieve the $5 \%$ swelling level. For the immersion test, note that no standard was referred to.

Evaluating Table I, the following points are worth noting:

1. Unlike most of the works dealing with swelling of rubber available in the literature, ${ }^{15,16}$ Table I provides the information on the time needed for the rubber specimens to achieve $5 \%$ swelling when they are in contact with solvents in the absence of mechanical stress (stress-free swelling). As highlighted in Loo et al., ${ }^{24}$ it is important to compare swollen 
rubbers at the same swelling degree to systematically evaluate their respective characteristics.

2. The fillers appear to modify significantly the swelling kinetics of the solvent in the swollen elastomer network. Comparing unfilled NBR and $40 \%$ filled NBR, the time needed to reach $5 \%$ swelling increases by three times in the case of $\mathrm{B} 0$ and by four times in the case of B100. The decrease of swelling kinetics with increasing amount of filler content has been widely observed and discussed in the literature. ${ }^{26-29}$ Nevertheless, in the presence of static tensile stress, where hydrostatic stress is negative, it was found that the filler could act as an accelerator for the solvent diffusion into rubber (i.e., decreasing the time needed for equilibrium swelling to occur). ${ }^{30}$

3. Comparing B0 and B100, it appears that a shorter duration is observed when B100 is used. Indeed, the immersion duration is shorter by four times and three times in the case of unfilled and filled rubbers, respectively. The fact that NBR swells faster in B100 than in B0 is classically explained in the literature by considering the high polarity of $\mathrm{B} 100 .{ }^{17,18}$

The percentage of volume change $(\Delta V \%)$ of the swollen rubber was calculated with the following equation in accordance with the ASTM D471 standard:

$$
\Delta V \%=\frac{\left(M_{3}-M_{4}\right)-\left(M_{1}-M_{2}\right)}{\left(M_{1}-M_{2}\right)} \times 100
$$

where $M_{1}$ is the initial mass of specimen in air, $M_{2}$ is the initial mass of specimen in water, $M_{3}$ is the mass of specimen in air after immersion, and $M_{4}$ is the mass of specimen in water after immersion. The degree of swelling, $J_{\mathrm{s}}$, is defined by the ratio between the volume of swollen specimen and that of the dry specimen. Hence, the $J_{\mathrm{s}}$ values for the swelling levels of $0 \%$ and $5 \%$ are 1 and 1.05 , respectively. In the following sections, the swelling in rubber specimens is described in terms of degree of swelling.

Remark 1. - The 5\% swelling is measured with respect to the compound (i.e., neglecting the fact that carbon black filler does not swell). Consequently, the rubber networks (matrix) are swollen to different extents between samples with different filler contents. Indeed, 5\% swelling in the compound corresponds to approximately $6 \%$ and $8 \%$ swelling of rubber matrix in $25 \%$ and $40 \%$ filled rubbers, respectively. This swelling variation is considered small because it does not yield to a significant modification of macroscopic mechanical response and fracture characteristics of swollen rubbers. ${ }^{31}$

Remark 2. - After immersion and before conducting any mechanical test, the swollen specimens were left for 7 days in air at room temperature to ensure homogeneous swelling. During this period, the mass of the swollen specimens was measured each day to observe any potential sample mass change (change of swelling level). It was found that the mass change after 7 days is negligible (ranging between $0 \%$ and $0.4 \%$ ), which suggests that no evaporation of solvent from the swollen rubber took place. Furthermore, the homogeneous swelling assumption was supported by the outcome of the glass transition temperature $\left(T_{g}\right)$ measurements at two different positions in the middle cross-sectional area of the rubber. As detailed in the Results and Discussion section, it was found that the $T_{g}$ at these two locations is essentially the same.

\section{MEASUREMENT OF GLASS TRANSITION TEMPERATURE $\left(\mathrm{T}_{\mathrm{G}}\right)$}

The glass transition temperature, $T_{\mathrm{g}}$, of dry and swollen rubbers was obtained using Metller Toledo differential scanning calorimetry (DSC). The mass of the rubber was confined between 4 to $10 \mathrm{mg}$ and heated from $-80^{\circ} \mathrm{C}$ to $0^{\circ} \mathrm{C}$. The heating rate was kept constant at $10^{\circ} \mathrm{C} / \mathrm{min}$ in a nitrogen atmosphere. 
TABLE II

GLASS TRANSITION TEMPERATURE OF DRY AND SWOLLEN NBR

\begin{tabular}{lcc}
\hline Rubber & Filler amount, \% & $\mathrm{T}_{\mathrm{g}},{ }^{\circ} \mathrm{C}$ \\
\hline Dry & 0 & -19.24 \\
& 25 & -19.70 \\
\multirow{3}{*}{ Swollen B100 } & 40 & -20.02 \\
& 0 & -25.92 \\
& 25 & -27.05 \\
Swollen B0 & 40 & -25.76 \\
& 0 & -19.39 \\
& 25 & -19.71 \\
& 40 & -20.70 \\
\hline
\end{tabular}

\section{UNIAXIAL CYCLIC TENSILE TEST}

Both dry and swollen rubbers were subjected to uniaxial cyclic tensile tests. All tests were conducted at room temperature using a $50 \mathrm{~N}$ Instron 5543 testing machine. The rubber was subjected to a cyclic test with increasing maximum stretch, denoted $\lambda$, defined as the ratio between current and initial length, up to a maximum stretch of 3 . The stretch was determined from the crosshead displacement. For each maximum stretch applied, the specimen underwent three cycles. Homemade grips prevented the specimen from slipping. The displacement rates were $3.33 \mathrm{~mm} / \mathrm{s}$ and $6.66 \mathrm{~mm} / \mathrm{s}$, whereas the corresponding strain rates were $0.08 \mathrm{~s}^{-1}$ and $0.016 \mathrm{~s}^{-1}$.

\section{RESULTS AND DISCUSSION}

In this section, the glass transition temperature for both dry and swollen rubbers is first analyzed. Subsequently, the stretch-stress response at both loading rates is described. The three main inelastic effects in the mechanical responses (i.e., hysteresis, stress softening, and permanent set) are discussed.

\section{GLASS TRANSITION TEMPERATURE}

The glass transition values, $\mathrm{T}_{\mathrm{g}}$, for both dry and swollen rubbers are shown in Table II. From this table, it is observed that the $\mathrm{T}_{\mathrm{g}}$ of the dry and swollen rubber is not affected by the different amount of carbon black. In fact, some of the previous studies have found that the $\mathrm{T}_{\mathrm{g}}$ of rubber is largely unaffected by carbon black fillers. ${ }^{32-34}$ Jung et al. ${ }^{35}$ have shown a very small increase of $\mathrm{T}_{\mathrm{g}}$ in NBR. However, they explained that this increase is not due to the increase of carbon black content but simply by its presence in the matrix. It appears that the effect of carbon black fillers on the $T_{g}$ of rubber remain unclear. Moreover, a certain amount of layer thickness of the physically adsorbed filler on rubber is needed to observe an effect of filler on the dynamic properties of rubber. ${ }^{33,36,37}$

In Table II, it is observed that the effect of $\mathrm{B} 100$ solvent on the $\mathrm{T}_{\mathrm{g}}$ is greater as compared with $\mathrm{B} 0$ solvent. In fact, the swollen $\mathrm{B} 0$ rubber showed no change of $\mathrm{T}_{\mathrm{g}}$ values. This could indicate that the expansion of free volume in the polymer due to the diffusion of solvent does not contribute to the change of $\mathrm{T}_{\mathrm{g}}$. The change of $\mathrm{T}_{\mathrm{g}}$ observed in swollen $\mathrm{B} 100$ rubber can be explained by the physical and chemical changes experienced due to the diffusion of solvent. ${ }^{38}$ Immersion of rubber in B100 solvent allows plasticizer extraction to occur physically and chemically. ${ }^{38-40}$ Once the extraction occurs, these empty sites are replaced by the absorbed aromatic component of the fuel diffused into the rubber. These components could act as pseudo-plasticizers and thereby shift the $\mathrm{T}_{\mathrm{g}}$ to lower 
values. ${ }^{40}$ Furthermore, new functional groups may have been generated at the carbon-carbon double bond due to the reaction between biodiesel and methylene or vinyl group of NBR. ${ }^{17}$ The chemical structure of these new functional groups could induce greater polymeric chain mobility and reduce the $T_{g}$ of swollen rubber. Indeed, one of the factors governing the mobility of polymeric chains is the polymer chemical structure. ${ }^{41}$

\section{STRETCH-STRESS}

The stretch-stress plots for both dry and swollen rubbers are shown in Figure 1. They are obtained with a displacement rate of $3.33 \mathrm{~mm} / \mathrm{s}$. Generally, both dry and swollen rubbers exhibit strong inelastic responses, especially for the case of filled rubbers. It is also observed that the stress decreases as the number of cycles increases for both dry and swollen rubber regardless of the imposed maximum stretch. This stress-softening phenomenon was first reported by Bouasse and Carrière. ${ }^{8}$ Later, it was studied more extensively by Mullins in $1947^{7}$ and was then referred to as the "Mullins effect." Despite the numerous studies reported in the literature after the work of these pioneers, no consensus has been found on the physical origin of the Mullins effect. Among the phenomena described, one can cite nonexhaustively bond rupture, ${ }^{42}$ chain rupture, ${ }^{43}$ chain slipping, ${ }^{44}$ chain disentanglement, ${ }^{45}$ filler-cluster breakdown, ${ }^{46,47}$ and network rearrangements. ${ }^{48,49}$ More recently, another interpretation based on interaction between fillers and rubber matrix was proposed. ${ }^{50}$

In this figure, the stiffness of swollen rubbers appears to be lower than the one of dry rubber. This decrease in rubber stiffness due to biodiesel diffusion has been widely observed and discussed in the literature. ${ }^{17-22}$ In their work, Horkay and $\operatorname{Lin}^{51}$ noted that the stiffness of a swollen polymer network is more sensitive to the concentration of network chains rather than the interaction between the polymer and the solvent. In other words, physical effects due to swelling are of first order compared with chemical effects. Indeed, because of the swelling phenomenon, the number of the molecular chains per unit volume decreases. Thus, the energy per unit volume needed to deform the swollen rubber decreases, which is consistent with the decrease in stiffness we have observed.

To probe more closely the effect of loading rates on the mechanical response of rubber, the stretch-stress plots for dry rubber at a given amount of filler are shown in Figure 2. From this figure, the response of rubber is observed to be similar for unfilled and $25 \%$ filled rubbers. Nevertheless, a large difference is observed for the $40 \%$ filled rubber. At maximum stretch of 2.5 , the stress in $0 \%$, $25 \%$, and $40 \%$ filled rubber increases by $6.5 \%, 5.7 \%$, and $45 \%$, respectively, whenever the loading rate is doubled. Indeed, the rate dependence response of rubber increases with the amount of filler. ${ }^{16}$ The stress-stretch responses of swollen rubbers with different amounts of filler content are not shown here because their trend on the rate-dependent response is similar to the dry rubber.

\section{HYSTERESIS}

This section aims at investigating the effect of swelling and filler content on the hysteresis loop. For the calculations, only the third cycles at each maximum stretch applied are used. Indeed, the third cycles are considered as stabilized because the mechanical response is almost similar from second cycles onward. Hysteresis can therefore be analyzed without being affected by accommodation effects.

Figure 3 shows the evolution of hysteresis loop area as a function of the maximum stretch applied for both dry and swollen rubbers at different loading rates. The values are given in $\mathrm{MJ} / \mathrm{m}^{3}$. The hysteresis loop area was found to increase with the amount of filler and maximum stretch in rubber for both loading rates. Indeed, fillers are subjected to debonding and breakdown when the rubber is stretched, ${ }^{52-54}$ which increases the level of energy lost and therefore the hysteresis loop 

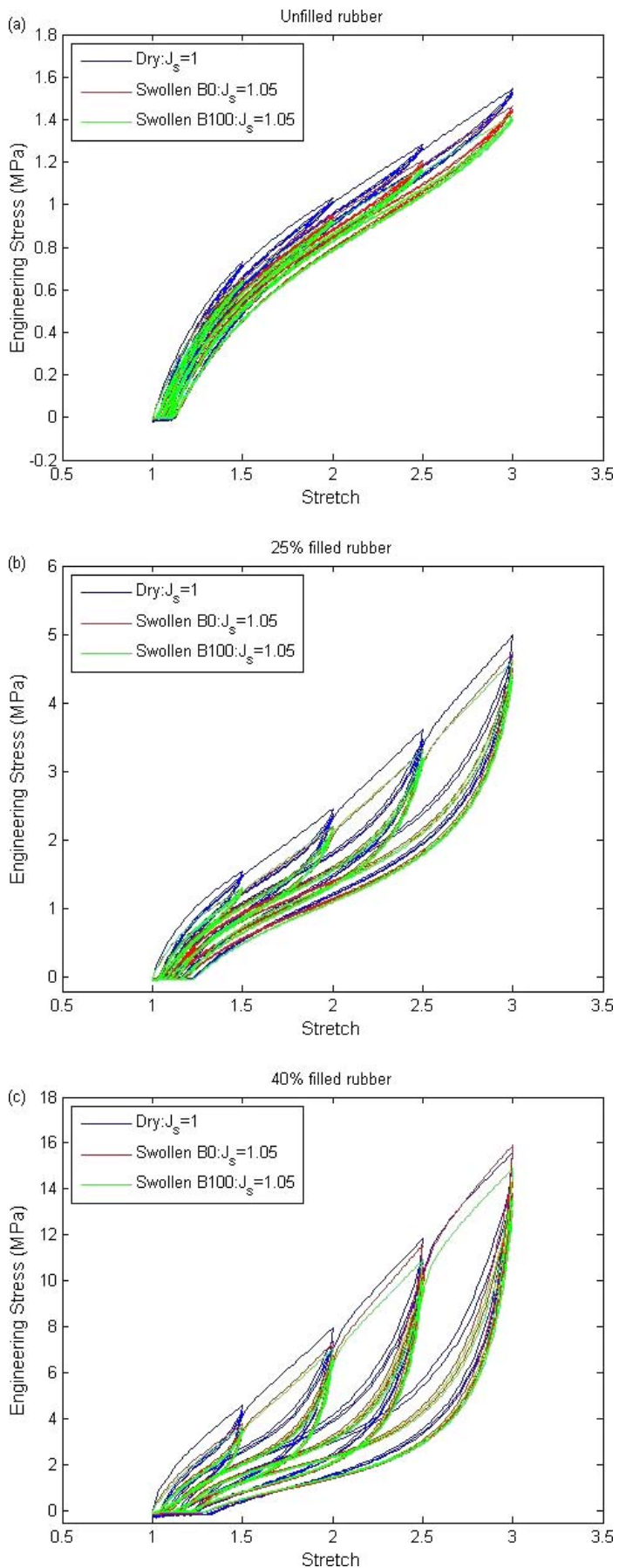

FIG. 1. - Stretch-stress plot for dry and swollen rubbers at $3.33 \mathrm{~mm} / \mathrm{s}$ : (a) unfilled rubber; (b) $25 \%$ filled rubber; (c) $40 \%$ filled rubber. 

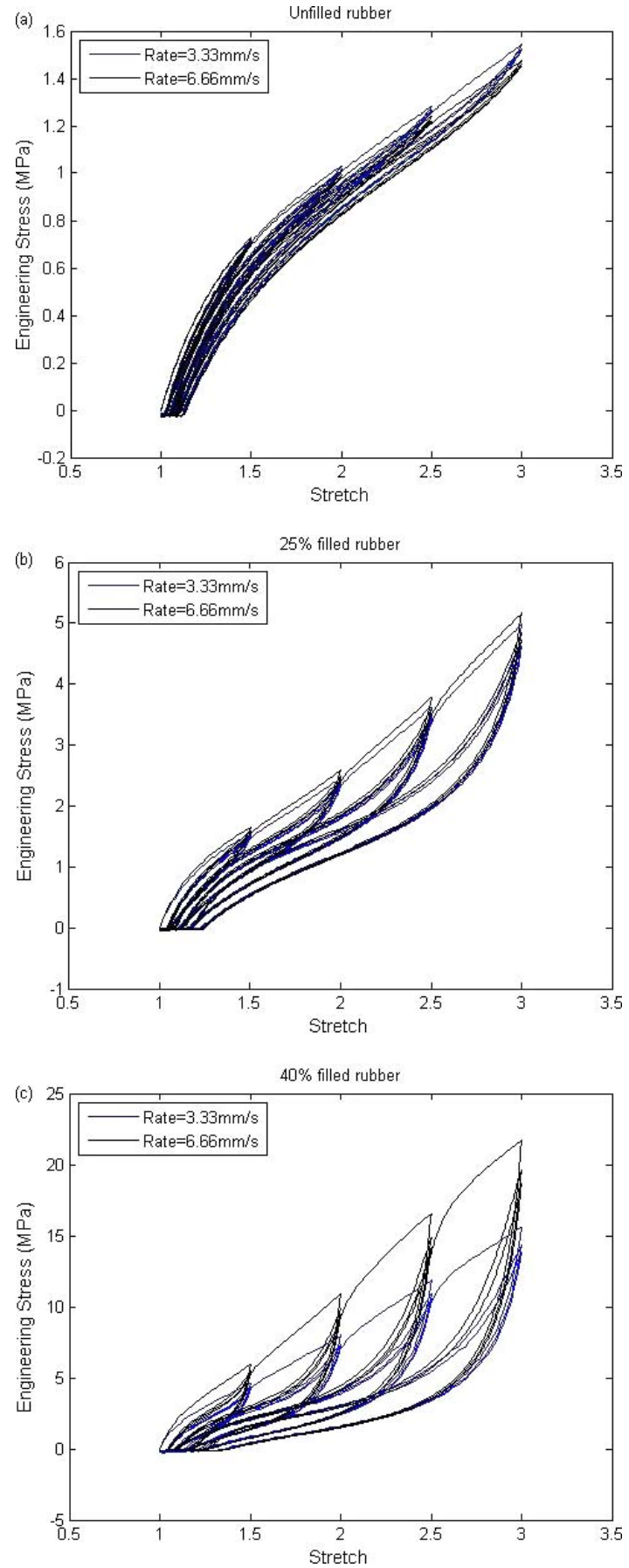

FIG. 2. - Stretch-stress plot for dry rubber at different loading rates: (a) unfilled rubber; (b) $25 \%$ filled rubber; (c) $40 \%$ filled rubber. 
(a) Unfilled rubber

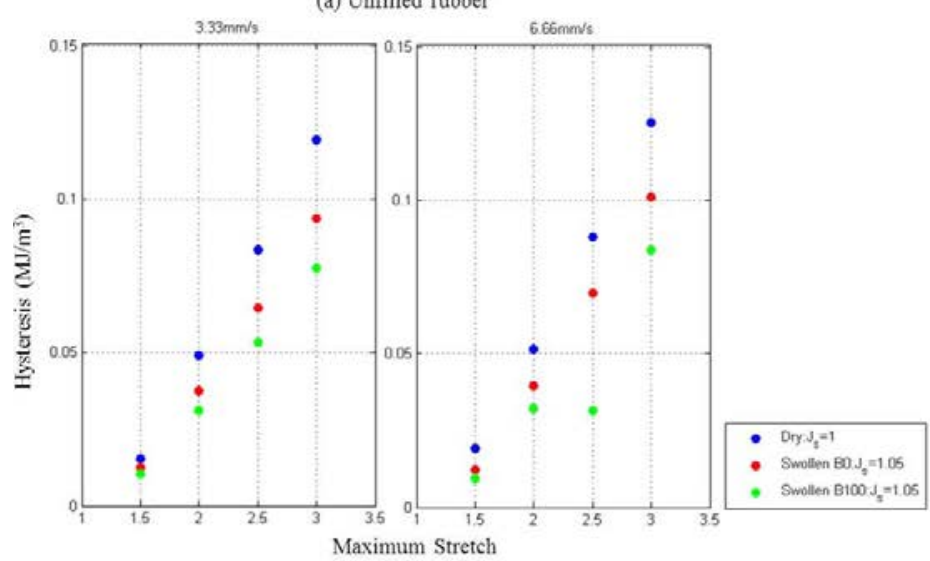

(b) $25 \%$ filled nubber

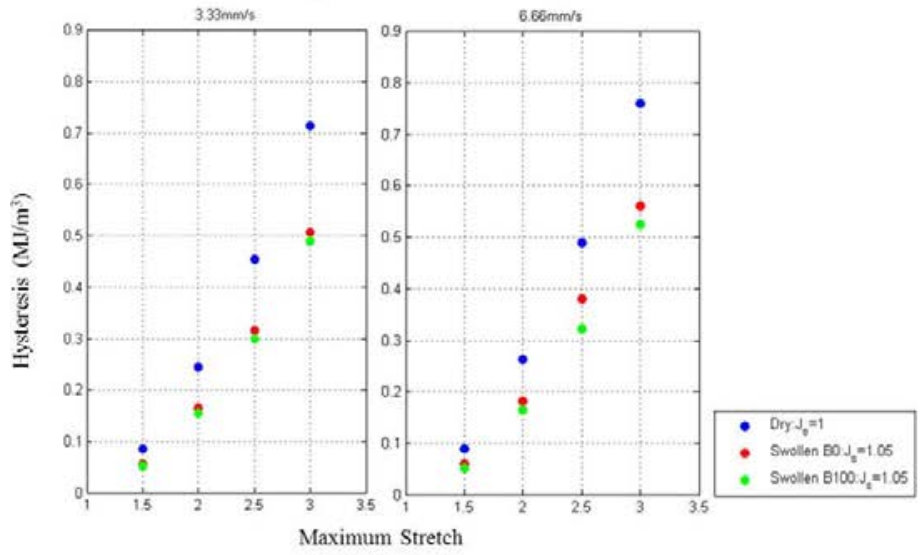

(c) $40 \%$ filled nubber

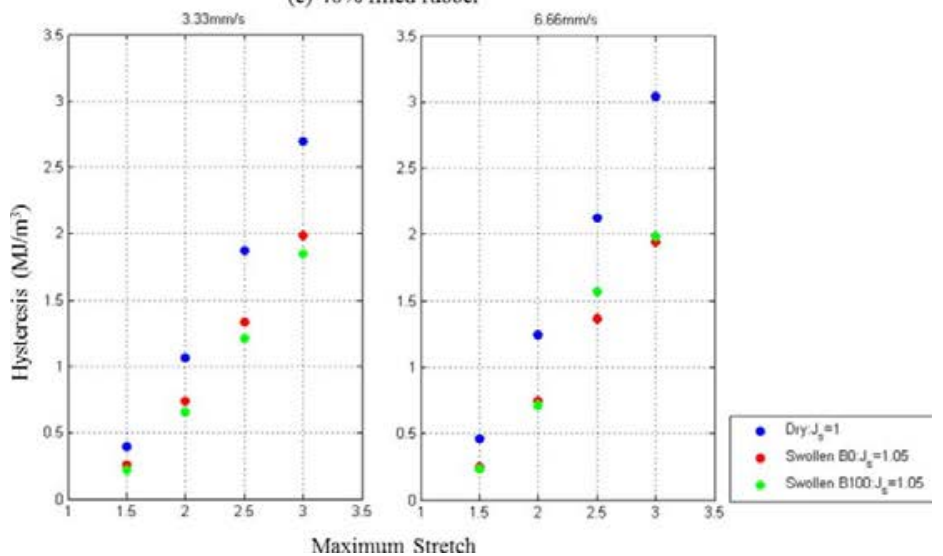

FIG. 3. - Hysteresis loop area for NBR at different loading rates: (a) unfilled rubber; (b) 25\% filled rubber; (c) $40 \%$ filled rubber. 
area. At a given amount of fillers and loading rate, the hysteresis is observed to be lower in swollen rubbers than in dry ones. ${ }^{52,54}$ This indicates that swelling not only reduces the stretch-stress response in Figure 1 but also reduces the hysteresis loop or energy loss. Furthermore, the effect of solvent type on the hysteresis loop area in filled rubbers appears to be not significant regardless of the loading rate.

Figure 4 shows the ratio of the hysteresis loop area over the strain energy during loading at the third cycle for both dry and swollen rubbers. The ratio is observed to be the highest in the dry rubber followed by swollen B0 and swollen B100 rubber regardless of loading rates and filler content. This indicates that the loss of energy is higher in dry rubber, which might be due to the higher amount of fillers-matrix debonding. In fact, the ratio of hysteresis to strain energy appears to be the highest in $40 \%$ filled rubber, which suggests that the corresponding debonding is more pronounced in $40 \%$ filled rubber. Along this line, the swollen B0 and B100 rubbers may already have experienced filler-matrix debonding because of chain scissioning or chemical interactions in the initial swollen state $^{18,24}$ (i.e., before the application of any mechanical loading). Consequently, the loss of energy in swollen rubber is constantly lower as compared with the dry rubber. Meanwhile, Kucherskii ${ }^{55}$ related the increase of hysteresis losses to the limited stretch ability of the rubber network. Finally, note that at a given amount of filler, the effect of solvent on the loss of energy is more pronounced in filled rubbers, as shown in Figure $4 \mathrm{a}$ and $4 \mathrm{~b}$. Indeed, immersion of rubber in B100 solvent presents a greater risk of fillers or additives extraction, leading to a lower ratio of energy loss as compared with dry rubber. ${ }^{38}$

\section{STRESS SOFTENING}

In the present study, the method used by Machado et al. ${ }^{56}$ was adopted to determine the amount of softening. This method allows us to remove the effect of hysteresis from the calculation. In their work, the measurement of the strain energy density is defined by:

$$
W=\int_{F} \pi: d F
$$

where $\pi$ is the nominal stress tensor, : is the double contraction, and $\boldsymbol{F}$ is the deformation gradient tensor. Under uniaxial tension, the strain energy density associated with the loading phase is calculated as follows:

$$
W_{L}=\int_{1}^{\lambda_{\max }} \pi_{1} d \lambda_{1}=\int_{1}^{\lambda_{\max }} \pi d \lambda
$$

In the literature, the second cycle is usually considered in calculation and in modeling the material response because softening, which takes place after the second cycle, is not significant. ${ }^{22,57}$ Therefore, the amount of softening can be determined by the ratio between the energies brought during the second $\left(\mathrm{W}_{2 \mathrm{~L}}\right)$ and first loads $\left(\mathrm{W}_{1 \mathrm{~L}}\right)$. Nevertheless, because the previous loadings applied at lower maximum stretches affect this ratio, we propose a new calculation that does not account for loading history. The aim of the calculation is to determine the strain energy density ( $\mathrm{W}_{1 \mathrm{~L}} *$ instead of $\mathrm{W}_{1 \mathrm{~L}}$ ) that would be obtained without the effects of previous cycles at lower maximum stretches. In Figure $5, \mathrm{~W}_{1 \mathrm{~L}}$ is given by area GDEF whereas $\mathrm{W}_{1 \mathrm{~L}} *$ is given by area OABCDEF. This approach considered that curve $\mathrm{OE}$ is close to the curve obtained under monotonic tensile condition (a first loading). Thus, the softening is higher whenever the ratio decreases regardless of the loading history. The ratio of these two energies $\frac{W_{2 L}}{W_{1 L^{*}}}$ at a given maximum stretch applied is plotted as a function of stretch at both loading rates in Figure 6. From the figure, it is first observed that the softening is significantly low in the case of unfilled dry and swollen NBR $\left(\frac{W_{2 L}}{W_{1 L}}>0.9\right)$. Moreover, 
(a) Unfilled rubber

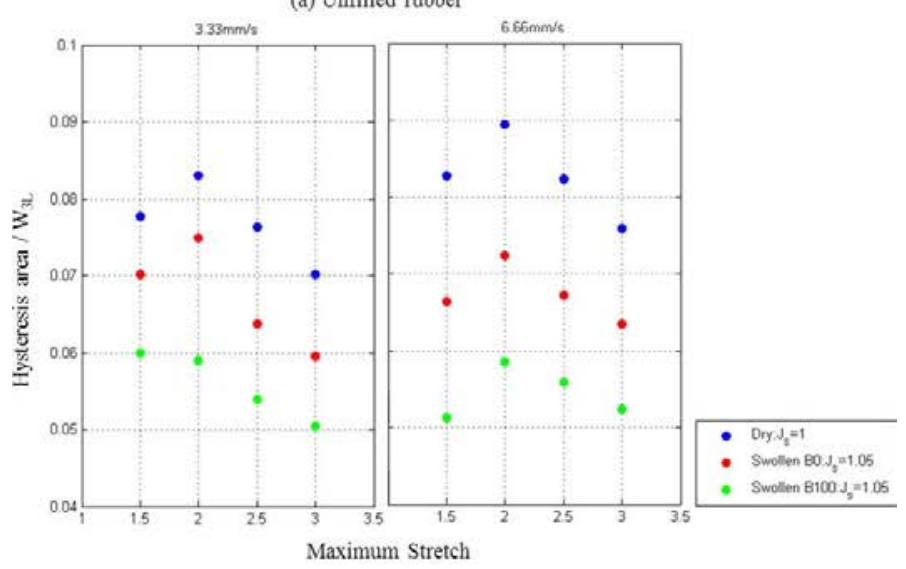

(b) $25 \%$ filled rubber

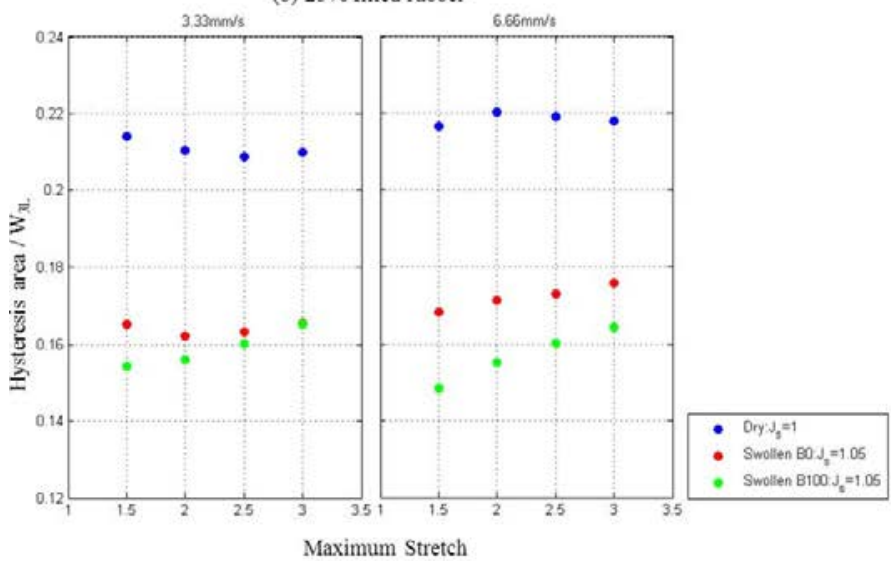

(c) $40 \%$ filled nubber

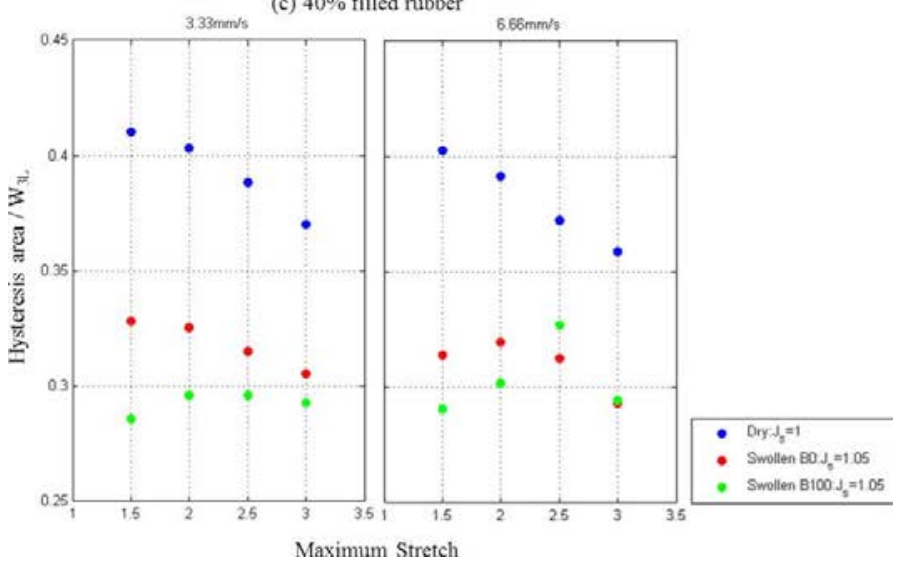

FIG. 4. - Ratio of dissipated energy: (a) unfilled rubber; (b) 25\% filled rubber; (c) $40 \%$ filled rubber. 


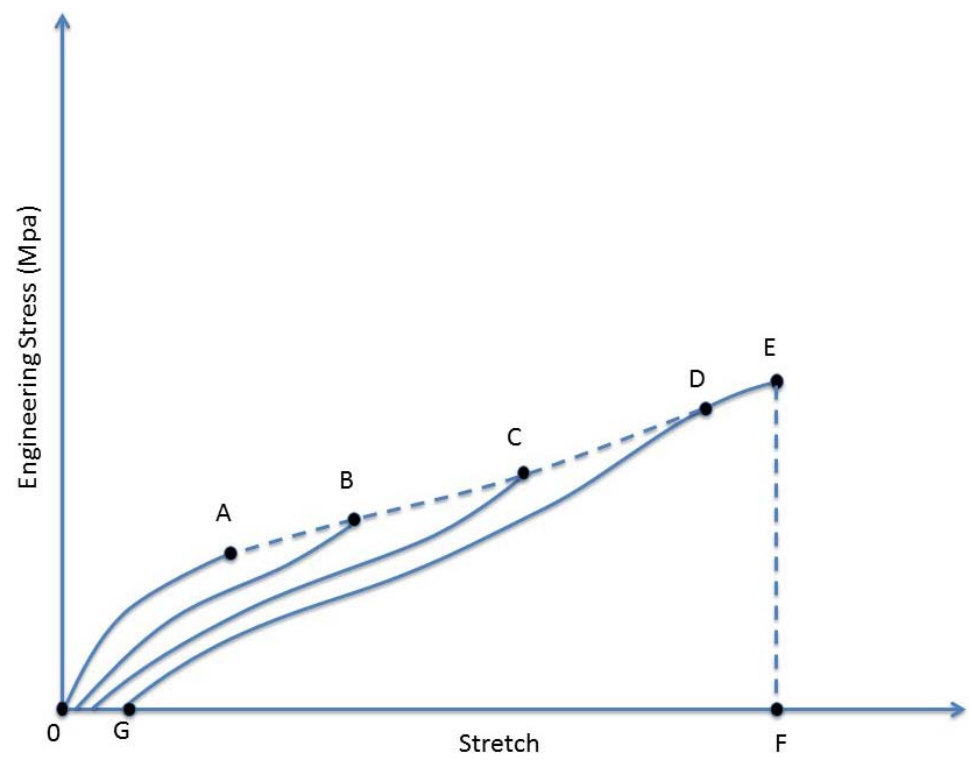

FIG. 5. - Illustration to determine the strain energy density.

concerning filled rubbers ( $25 \%$ and $40 \%$ in red and green markers, respectively), the softening is strongly affected by the addition of fillers and is amplified by the level of stretch applied.

For both dry and swollen rubbers, the amount of softening is observed to be the highest when the filler content is $40 \%$. Indeed, softening is more pronounced in rubbers with a high amount of fillers. One of the proposed mechanisms for this phenomenon was filler rupture when the rubber is stretched, causing the rubber stiffness to decrease significantly. ${ }^{46}$ The overall effect of solvent and loading rate is not seen as significant in Figure 6. However, the softening appears to be lower in

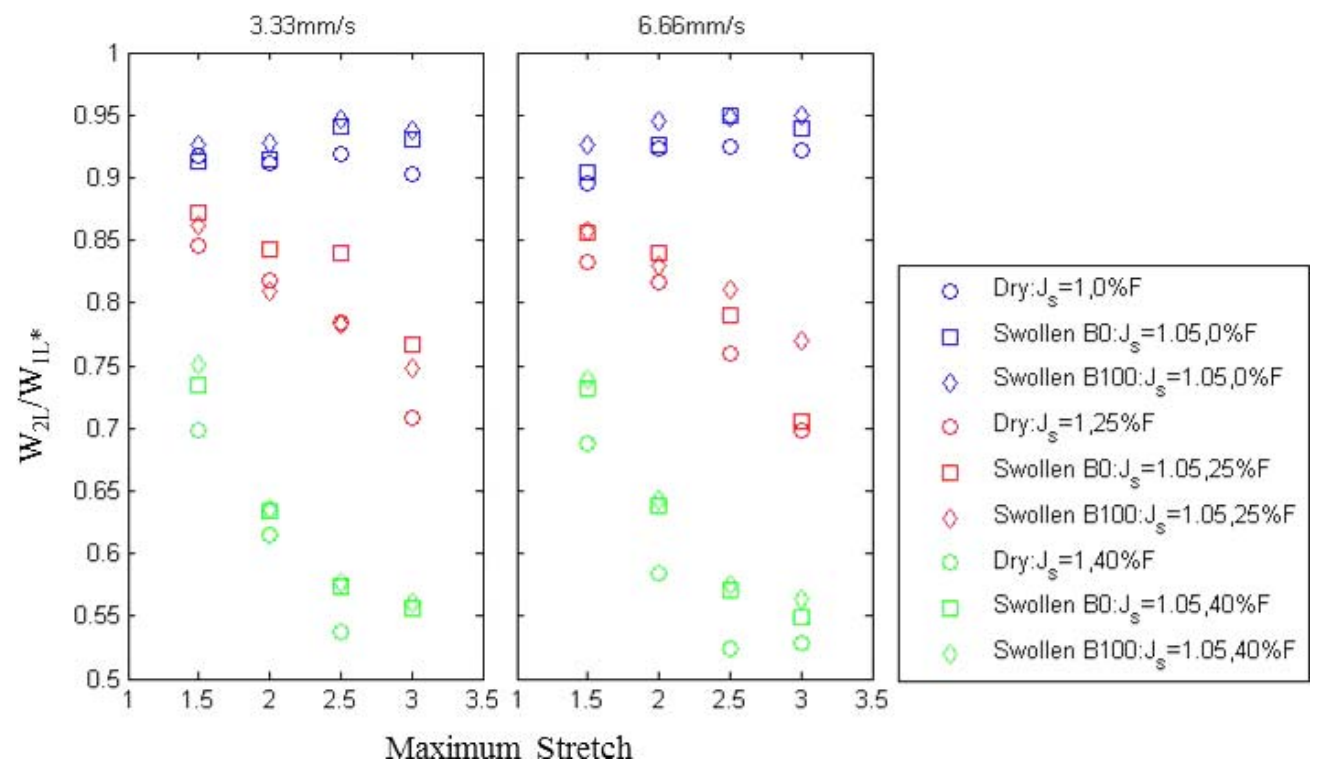

FIG. 6. — Ratio for dry and swollen rubber at $3.33 \mathrm{~mm} / \mathrm{s}$ and $6.66 \mathrm{~mm} / \mathrm{s}$. 
(a) Loading rate $=3.33 \mathrm{~mm} / \mathrm{s}$
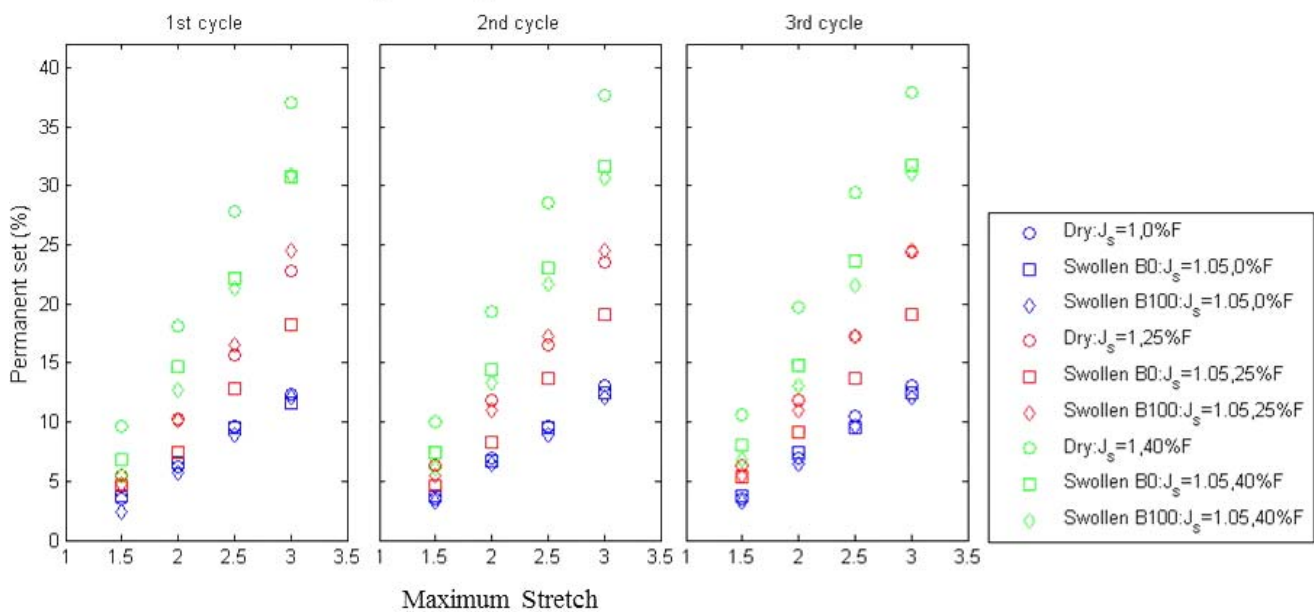

(b) Loading rate $=6.66 \mathrm{~mm} / \mathrm{s}$
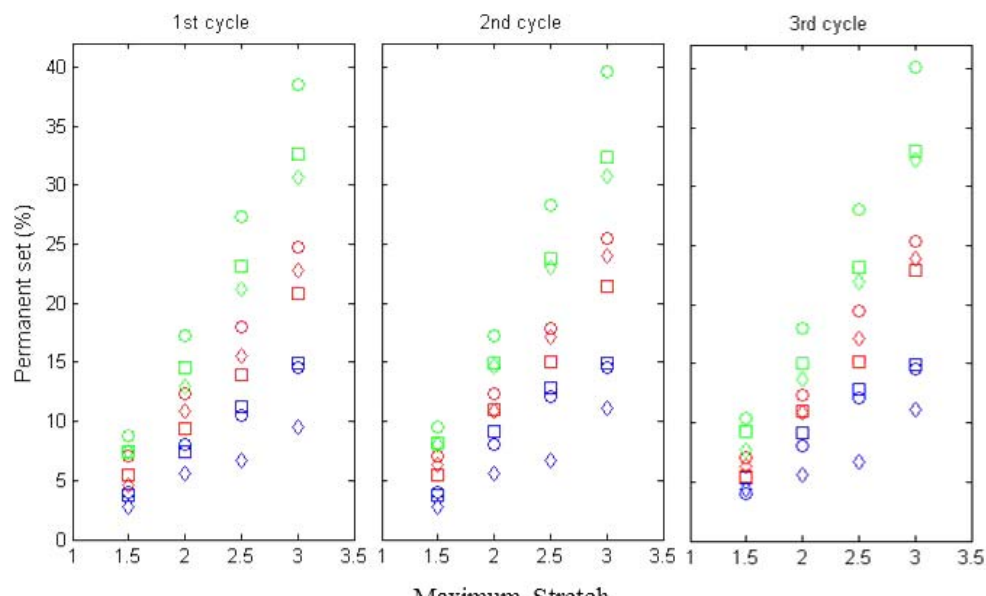

$\begin{array}{ll}0 & \text { Dry } \cdot J_{s}=1,0 \% \mathrm{~F} \\ \square & \text { Swollen } B 0: J_{s}=1.05,0 \% \mathrm{~F} \\ \diamond & \text { Swollen } B 100 \cdot J_{s}=1.05,0 \% \mathrm{~F} \\ 0 & \text { Dry } J_{s}=1,25 \% \mathrm{~F} \\ \square & \text { Swollen } B 0 \cdot J_{s}=1.05,25 \% \mathrm{~F} \\ \diamond & \text { Swollen } B 100 \cdot J_{s}=1.05,25 \% \mathrm{~F} \\ & \text { Dry. } J_{s}=1,40 \% \mathrm{~F} \\ \square & \text { Swollen } B 0 \cdot J_{s}=1.05,40 \% \mathrm{~F} \\ & \text { Swollen } B 100: J_{s}=1.05,40 \% \mathrm{~F}\end{array}$

FIG. 7. - Percentage of permanent set for dry and swollen rubber at loading rate of (a) $3.33 \mathrm{~mm} / \mathrm{s}$ and (b) $6.66 \mathrm{~mm} / \mathrm{s}$.

swollen $40 \%$ filled rubbers when stretched at $6.66 \mathrm{~mm} / \mathrm{s}$. Some of the reported work has observed that swelling decreases stress softening..$^{20,22,57}$

\section{PERMANENT SET}

The permanent set is determined by identifying the residual stretch at the end of each loop cycle, and the percentage of the increase from the origin $(\lambda=1)$ is calculated. Figure $7 \mathrm{a}$ and $7 \mathrm{~b}$ show the percentage of permanent set for both dry and swollen rubbers when stretched at $3.33 \mathrm{~mm} / \mathrm{s}$ and $6.66 \mathrm{~mm} / \mathrm{s}$, respectively. In this figure, it is observed that the permanent set increases with the amount of fillers and stretch at both loading rates. In fact, the values are slightly higher when the rubber is stretched at $6.66 \mathrm{~mm} / \mathrm{s}$. The permanent set is higher whenever the material has a shorter time to return to its origin because of higher stretching or increased loading rate. Dorfmann and $\operatorname{Ogden}^{58}$ have reported similar results. The authors observed that residual extensions increased with 
the amount of fillers and with the applied amplitude of stretching. Boyce et al. ${ }^{59}$ reported that the residual strain increases whenever the loading rate is intensified.

Generally, it is observed that swelling reduces permanent set especially for highly filled rubbers (green markers). This observation has also been reported in Andriyana et al. ${ }^{57}$ for different swelling levels in swollen NBR. However, swelling does not seem to have a significant effect in the case of unfilled rubbers (blue markers) except for swollen B100 rubber at a high loading rate, where values were relatively lower than those of its counterpart. Finally, comparing filled B100 swollen rubbers and their B0 counterpart, regardless of the loading rate, it appears that permanent set is systematically lower in swollen B0 rubber than in swollen B100 rubber for $25 \%$ filler content, whereas the opposite is observed for $40 \%$ filler content. The corresponding observation highlights a complex interaction between matrix, filler, and solvent.

\section{CONCLUSION}

The effect of solvent, amount of filler, and loading rate on the mechanical response of NBR under uniaxial tensile cyclic loading has been investigated. The fillers appear to increase the resistance of elastomeric network to swelling. Generally, both dry and swollen rubbers exhibit strong inelastic responses, especially for the case of filled rubbers, regardless of the loading rates. The mechanical response of rubber is observed to be very similar for unfilled and $25 \%$ filled rubbers at different loading rates, whereas a large difference is observed for the $40 \%$ filled rubber. It is observed that swelling decreases not only the stretch-stress response but also stiffness, hysteresis, stress softening, and permanent set. The effect of solvent type on hysteresis is more apparent in filled rubbers as compared with unfilled rubbers. No significant effect of solvent on softening is observed. Most of the inelastic responses of rubber are observed to be different between filled and unfilled swollen rubbers. The difference is especially higher for the $40 \%$ filled rubber. The presence of solvent in filled rubber might have influenced the interaction between rubber matrix and filler when exposed to solvents, leading to the different trend observed. Future work on the study of the mechanism in each phenomenon should be considered to understand further the behavior of swollen filled rubbers under a cyclic condition.

\section{ACKNOWLEDGEMENT}

This work was supported by the Ministry of Higher Education Malaysia through High Impact Research grant MOHE-HIR D000008-16001, by the University of Malaya through University of Malaya Research grant UMRG RP022B-13AET, and by the Embassy of France in Malaysia. This work was also supported by an AIS Scientific Grant from Rennes Métropole (2012), Mission of Resources and Skills Technology (MRCT) grant from French National Center for Scientific Research (2012), and Mission for Interdisciplinary (MI) grant from the French National Center for Scientific Research (2013). The authors would like to thank Mr. Mohd. Said Bin Sakat from the University of Malaya for his assistance during the preparation of samples for the DSC test.

\section{REFERENCES}

\footnotetext{
${ }^{1}$ R. Rajasekar, K. Pal, G. Heinrich, A. Das, and C. Das, Mater. Design 30, 3839 (2009).

${ }^{2}$ Q. Wang, F. Yang, Q. Yang, J. Chen, and H. Guan, Mater. Design 31, 1023 (2010).

${ }^{3}$ M. Balachandran, S. Devanathan, R. Muraleekrishnan, and S. Bhagawan, Mater. Design 35, 854 (2012).

${ }^{4}$ J. Diani, B. Fayolle, and P. Gilormini, Eur. Polym. J. 45, 601 (2009).

${ }^{5}$ W. V. Mars, “Multiaxial Fatigue of Rubber,” Ph.D. Thesis, University of Toledo, 2001.
} 
${ }^{6}$ J. S. Martinez, J.-B. Le Cam, X. Balandraud, E. Toussaint, and J. Caillard, Polymer 54, 2727 (2013).

${ }^{7}$ L. Mullins, J. Rubber Res. 16, 275 (1947).

${ }^{8}$ H. Bouasse and Z. Carrière, Annales de la Faculté des Sciences 5, 257 (1903)

${ }^{9}$ W. Mars, A. Fatemi, J. Eng. Mater. Technol. 126, 19 (2004).

${ }^{10}$ J. Diani, Y. Merckel, M. Brieu, and J. Caillard, RubBER CHEM. TECHNOL. 86, 572 (2013).

${ }^{11}$ L. Mullins, RuBber CHEM. TECHNOL. 22, 1036 (1949).

${ }^{12}$ S. Sumathi, S. Chai, and A. Mohamed, Renew. Sustain. Ener. Re. 12, 2404 (2008).

${ }^{13}$ S. Alves, V. Mello, and J. Medeiros, Tribol. Int. 65, 74 (2013).

${ }^{14}$ I. Mukherjee and B. K. Sovacool, Renew. Sustain. Ener. Rev. 37, 1 (2014).

${ }^{15}$ C. Chandrasekaran, Rubber Seals for Fluid and Hydraulic Systems, William Andrew, Norwich, NY, 2009.

${ }^{16}$ A. N. Gent, Engineering with Rubber: How to Design Rubber Components, Carl Hanser Verlag Munich, 2012.

${ }^{17}$ A. S. M. A. Haseeb, H. H. Masjuki, C. T. Siang, and M. A. Fazal, Renew. Ener. 35, 2356 (2010)

${ }^{18}$ A. S. M. A. Haseeb, T. S. Jun, M. A. Fazal, H. H. Masjuki, Energy 36, 1814 (2011).

${ }^{19}$ S. Ch'ng, A. Andriyana, E. Verron, O. Kahbasi, and R. Ahmad, Exp. Mech. 53, 1323 (2013).

${ }^{20}$ A. Andriyana, A. B. Chai, E. Verron, and M. R. Johan, Mech. Res. Commun. 43, 80 (2012).

${ }^{21}$ A. B. Chai, A. Andriyana, E. Verron, M. R. Johan, and A. S. M. A. Haseeb, Polym. Test. 30, 867 (2011).

${ }^{22}$ A. B. Chai, A. Andriyana, E. Verron, and M. R. Johan, Mater. Des. 44, 566 (2013).

${ }^{23}$ S. Jerrams, J. Hanley, N. Murphy, and H. Ali, RUBbER CHEM. TeCHNOL. 81, 638 (2008).

${ }^{24}$ M. S. Loo, J.-B. Le Cam, A. Andriyana, E. Robin, and A. Afifi, Int. J. Fatigue 74, 132 (2015).

${ }^{25}$ ASTM D412, “Tensile Strength Properties of Rubber and Elastomers," Standard Test Methods for Vulcanized Rubber and Thermoplastic Elastomers-Tension, ASTM International, West Conshohocken, PA, 2013.

${ }^{26}$ L. R. G. Treloar, The Physics of Rubber Elasticity, Oxford University Press, 1975.

${ }^{27}$ K. Fukumori, T. Kurauchi, and O. Kamigaito, Polymer 31, 2361 (1990).

${ }^{28}$ H. Ismail, R. Jaffri, and H. Rozman, J. Elastomers Plast. 35, 181 (2003).

${ }^{29}$ H. Hassan, E. Ateia, N. Darwish, S. Halim, and A. A. El-Aziz, Mater. Design 34, 533 (2012).

${ }^{30}$ S. Y. Ch'ng, A. Andriyana, Y. L. Tee, and E. Verron, Materials 8, 884 (2015).

${ }^{31}$ M. Loo, J.-B. Le Cam, A. Andriyana, E. Robin, and J. Coulon, Polym. Degrad. Stab. 12415 (2016).

${ }^{32}$ M. Baccaredda and E. Butta, J. Polym. Sci. A Polym. Chem. 57, 617 (1962).

${ }^{33}$ P. Smit, RubBer CHEM. TeCHNOL. 41, 1194 (1968).

${ }^{34}$ Z. Jun-Xue, W. He, S. Xin-Yan, and Z. Shu-Gao, J. Macromol. Sci. B 51, 496 (2012).

${ }^{35}$ K. I. Jung, S. W. Yoon, S. J. Sung, abd J. K. Park, J. Appl. Polym. Sci. 2004, 94, 678-683.

${ }^{36} \mathrm{G}$. Kraus, K. Rollmann, and J. Gruver, Macromolecules 3, 92 (1970).

${ }^{37}$ S. Kaufman, W. Slichter, and D. Davis, J. Polym. Sci. A-2 Polym. Phys. 9, 829 (1971)

${ }^{38}$ E. Richaud, F. Djouani, B. Fayolle, J. Verdi, and B. Flaconneche, Oil Gas Sci. Technol. Rev. IFP Energies nouvelles 70, 317 (2013)

${ }^{39}$ W. Trakarnpruk and S. Porntangjitlikit, Renew. Ener. 33, 1558 (2008).

${ }^{40}$ R. J. Pazur, T. Kennedy, RubBer Chem. TeChnOl. 88, 324 (2015)

${ }^{41}$ R. J. Young and P. A. Lovell, Introduction to Polymers, CRC Press, Boca Raton, FL, 2011.

${ }^{42}$ A. Blanchard and D. Parkinson, Ind. Eng. Chem. 4, 799 (1952).

${ }^{43}$ F. Bueche, J. Appl. Polym. Sci. 4, 107 (1960).

${ }^{44}$ R. Houwink, RubBer CHEM. TeChnOL. 29, 888 (1956).

${ }^{45}$ G. R. Hamed and S. Hatfield, RuBBER CHEM. TECHNOL. 62, 143 (1989).

${ }^{46}$ G. Kraus, C. W. Childers, and K. W. Rollmann, J. Appl. Polym. Sci. 10, 229 (1966).

${ }^{47}$ M. Klüppel and J. Schramm, Macromol. Theory Simulat. 9, 742 (2000).

${ }^{48}$ G. Marckmann, E. Verron, L. Gornet, G. Chagnon, P. Charrier, P. Fort, J. Mech. Phys. Solids 50, 2011 (2002). 
${ }^{49}$ J. Diani, M. Brieu, and J. M. Vacherand, Eur. J. Mech. A Solids 25, 483 (2006).

${ }^{50}$ R. Diaz, J. Diani, P. Gilormini, Polymer 55, 4942 (2014).

${ }^{51}$ F. Horkay and D. C. Lin, Langmuir 25, 8735 (2009).

${ }^{52}$ J. A. C. Harwood and A. R. Payne, RUBber CHEM. TECHNOL. 40, 840 (1967).

${ }^{53}$ J.-B. Donnet, Carbon Black: Science and Technology, CRC Press, Boca Raton, FL, 1993.

${ }^{54}$ J. T. Bauman, Fatigue, Stress, and Strain of Rubber Components: Guide for Design Engineers, Carl Hanser Verlag, Munich, 2012.

${ }^{55}$ A. Kucherskii, Polym. Test. 24, 733 (2005).

${ }^{56}$ G. Machado, G. Chagnon, and D. Favier, Mech. Mater. 42, 841 (2010).

${ }^{57}$ A. Andriyana, M. S. Loo, G. Chagnon, E. Verron, and S. Y. Ch'ng, Int. J. Eng. Sci. 95, 1 (2015)

${ }^{58}$ A. Dorfmann and R. W. Ogden, Int. J. Solids Struct. 41, 1855 (2004).

${ }^{59}$ M. C. Boyce, K. Kear, S. Socrate, and K. Shaw, J. Mech. Phys. Solids 49, 1073 (2001). 